\title{
Development of a Hybrid Agile Management Model in Local Self-Government Units
}

\author{
Diana CAR-PUŠIĆ*, Ivan MAROVIĆ, Goran BULATOVIĆ
}

\begin{abstract}
Local self-government units (LSGUs) often view project management as an accompanying activity not really giving it the appropriate level of importance. Challenges of traditional project management where the projects are segmented into discrete paths each dependent on the completion of the previous phase but without feedback or iteration can be overwhelming in a rigid governmental organizational structures. Such could be avoided by changing the way the projects are managed and/or changing the organizational structure. In both cases agile approach can be helpful. However, a priori implementation can cause more damage than good. It is the thinking behind the Agile principles that would adapt to the needs and particularities of the work environment it is implemented in, especially in light of the variety of activities of government bodies. The proposed model, Hybrid Agile Model, aims at defining a new, flexible, management structure for local self-government units, based on the development of human resources and constant change of culture, never neglecting the regular activities of such bodies, and all while making them more reliable and effective. The model has been described in detail along with the implementation process that has been tested on LSGU City of Poreč
\end{abstract}

Keywords: Agile project management; DSDM; case study; organizational structure; Scrum; traditional project management

\section{INTRODUCTION}

Local self-government units (LSGUs) often view project management as an accompanying activity not really giving it the appropriate level of importance. A number of problems lies in the system of functioning of local and regional self-government that have been detected through practical experience, as well as scientific research. In the Republic of Croatia, those problems are explicitly stated in the National Public Administration Development Strategy 2015-2020 [1], and are manifested in several segments of functioning, including the professional project part, which is the subject of this research.

In the LSGUs, as a part of the public administration system, the problems according to the Strategy 2015-2020 have been identified and summed up into three groups, and can serve as a basis for developing a hybrid agile management model (Fig. 1). These problems are related and therefore should be systematically approached. Every prioritization or partial approach in their solving can cause more harm than good.

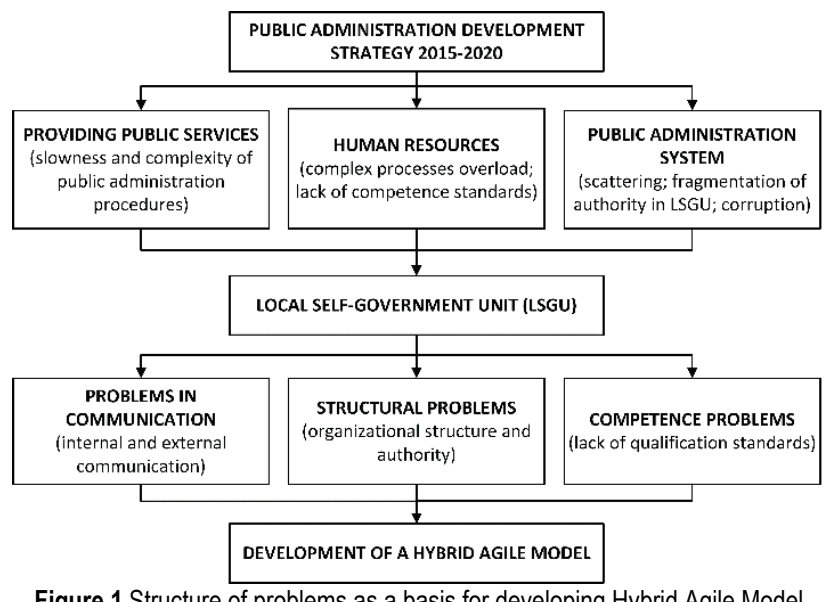

Figure 1 Structure of problems as a basis for developing Hybrid Agile Model

According to the aforementioned, problems in LSGU are grouped into three related entities:

- Communication problems - all communication problems within LSGU bodies as well as between LSGU bodies, and communication with users
- Structural problems - issues related to the LSGU system, organizational structure and authority

- Competence problems - issues related to standardization of qualifications and professional development.

Most LSGUs deal with managing projects in traditional manner by applying one of project management methodologies such as IPMA [2] or PMI [3]. This is often challenging because of the organizational structure and aforementioned problems rather than project itself. Some researchers show success by modelling management information systems and applying specific multi-criteria approach in managing various construction and infrastructure projects [4-9] but they do not cope with changing organizational structure of a LSGU. Sensitivity of organizational structure, even at project team level, is highly sensitive and impact can be immense [10]. The purpose of this research is to develop a hybrid agile organizational model that is more suitable for (1) managing projects in LSGUs, and (2) changing the management model within the organization. Therefore, the new model is considered more advanced for restructuring of the organizational scheme from a functional type to a more flexible one (matrix) by adopting a series of Agile management principles. These principles are derived from Agile Manifesto [11]. The focus is placed on structural and management organizational scheme together with the basic indications of the roles, authority and interrelations. The communication and competence framework will be identified in the form of guidelines for further research. The model is tested on a case study of the city of Poreč.

\section{RESEARCH BACKGROUND}

In 2006 Vinekar et al. [12] stated that agile development and traditional development have different views on teamwork. While agile development is characterized by collaborative work, the traditional development focuses on individual work, specialized skills and larger teams. The careful organizational structure is a key of success for construction projects [13] where fostering of organizational culture is considered to be of most importance. Lindsjorn et al. [14] argued that despite claims of the importance of teamwork in agile teams they 
did not find teamwork quality to be higher than in traditional teams. Their survey showed that the effect of teamwork quality on team performance was only marginally greater for the agile teams than for the traditional teams.

The key characteristics of agile methods are lean, flexibility and highly iterative development with a strong emphasis on stakeholder involvement [15]. In looking towards agile implementation [16], the concept works better if it is implemented for tiny advancements at process levels of a project. Saini et al. [17] investigated the critical success factors associated with the effectiveness of transfer and sharing of tacit knowledge in lean and agile construction processes. They concluded that both concepts require the collaboration between the source and recipient of knowledge to create new knowledge, and could be used as organizational learning tool in managing construction processes. Streule et al. [18] used one of agile methods (Scrum method [19, 20]) and investigated the implementation possibilities of such framework into the construction industry. Their study show that the Scrum has great potential in the design and planning departments of construction firms. The use of agile methods gives more flexibility or as [17] stated "the ability to both create and respond to change in order to profit in a turbulent business environment". Additionally, [18] gave recommendation about the use of Scrum method in the design phase and proposed an outlook to implement Scrum in other phases of construction projects. Sweetman \& Conboy [21] referred that agile approaches can be extremely effective at project level, they can impose significant complexity and a need for adaptiveness at the project portfolio level.

In 2013 Boer \& van Engers [22] highlighted the importance of agile approach implementation in public administration as an acceptable tool for change of regulatory policy and define policy proposals in multistakeholder environment. Nouttila et al. [23] contribute to research by using agile practices specifically in the context of public organizations. Throughout the research authors shed the light on the challenges public organizations i.e. governmental offices may face while adopting agile methods in managing their projects. The identified challenges were related, among the others, to documentation, personnel education, experience and commitment, stakeholder communication and their involvement, roles in an agile set-up, location of the agile teams, and legislation. Authors suggested that more research on the management of projects utilizing agile methods should be conducted in the future, focused on the project role definitions in an agile set-up, and the agile forms of organizing in the public sector. On the other hand, in 2016 Simoyama et al. [24] presented the results obtained from the adaptation and implementation of Scrum method as an agile project management tool in a government agency. They use Scrum for managing projects in defined organization and found out that agile way improved the efficiency to the project deliverables without any loss in the quality of the intermediary and final products.

In 2018 Lappi et al. [25] gave a systematic literature overview of the previous agile literature in order to identify and categorize agile project governance practices. They identified several new practices emerging in agile projects that will provide better understanding of agile approaches to project management. The implications of their study could enable managers to identify and apply feasible governance practices that can support better agile project performance. Narbon-Perpina \& De Witte [26] provided a systematic review of the existing literature on local government efficiency from a global point of view covering scientific articles (using search engines Web of Science and Scopus) from 1990 up to the year 2016. Both of these papers deal with how an organization should deal with agile principles in managing projects, but not to apply agile principles on the organization itself.

\section{DEVELOPMENT OF A HYBRID AGILE MANAGEMENT MODEL IN LOCAL SELF-GOVERNMENT UNITS}

In accordance with the legal obligations, the usual management and organization structure of LSGUs is of a functional type. According to the Law on Local and Regional Self-Government (Official Gazette NN 19/13), the City Council is a representative body that makes decisions, while the executive function is performed by elected mayors and their deputies. Administrative bodies, i.e. administrative departments and sections, are established to carry out tasks within their scope. These problems became especially important due to the accession of Croatia to the EU 2013, i.e. with the increased possibilities of withdrawal of funds available for projects from EU funds. This resulted in adopting the Regional Development Act of the Republic of Croatia (Official Gazette NN 147/14), which contributed to the creation of conditions for more efficient withdrawal of funds. Common ways to respond to these risks are known by introducing more flexible organizational structures: project and matrix structures. Due to the statutory legal framework, the introduction of such solutions in LSGUs requires increased attention and re-examination of opportunities and risks.

\subsection{Main Concept and Basis of Model Development}

The basic idea is that the usual way of implementing projects in LSGUs could be significantly improved by introducing a matrix organizational structure supported by Agile working framework in the implementation of business processes. Therefore, a new model called the Hybrid Agile Model (HAM) is proposed. The proposed model is based on authors' previous research [27]. Basically, it is a matrix model with an improved Agile framework at the business process organization level. In the present circumstances, it is estimated that HAM represents an optimal transitional solution to more developed organizational forms that will, at a reasonable financial cost, contribute to a more efficient functioning of local and regional self-government, in particular in the field of professional and project affairs.

The existing research and practice, as well as valid legislative framework in the Republic of Croatia, point to the impossibility of introducing clean Agile. This leads to the incremental introduction of hybrid model, such as HAM, which should provide balanced synergy of the matrix structure and application of the Agile principles.

\subsection{Steps in Model Development Application}

It is certain that the development and implementation of the model will take place gradually, through several phases. At each stage, the achieved solution must meet the 
requirements of optimal LSGU functioning and represent an incremental improvement over the previous state. The phases are not strictly separated but partly overlap, while dynamics and intensity of implementation depend on the assessment of circumstances in a specific environment.

The development and implementation of the model foresees the following basic steps:

- Defining the basic organizational structure

- Defining roles, authority and interrelationships based on Agile principles

- Defining the communication model (functional and project communication channels need to be defined)

- Defining the required competences

- $\quad$ Phase implementation of the model.

\subsection{Process Management}

Project Process Management is based on a balanced application of Agile principles in the project environment with incremental implementation of Scrum and Dynamic Systems Development Method (DSDM) Agile working framework. The DSDM framework is appropriate due to the classification of roles and powers as business, technical and management roles [28]. It has been estimated that Scrum "... belongs to more versatile methods ... or process management frameworks, whose principles go beyond the often exclusive software development environment", [29].
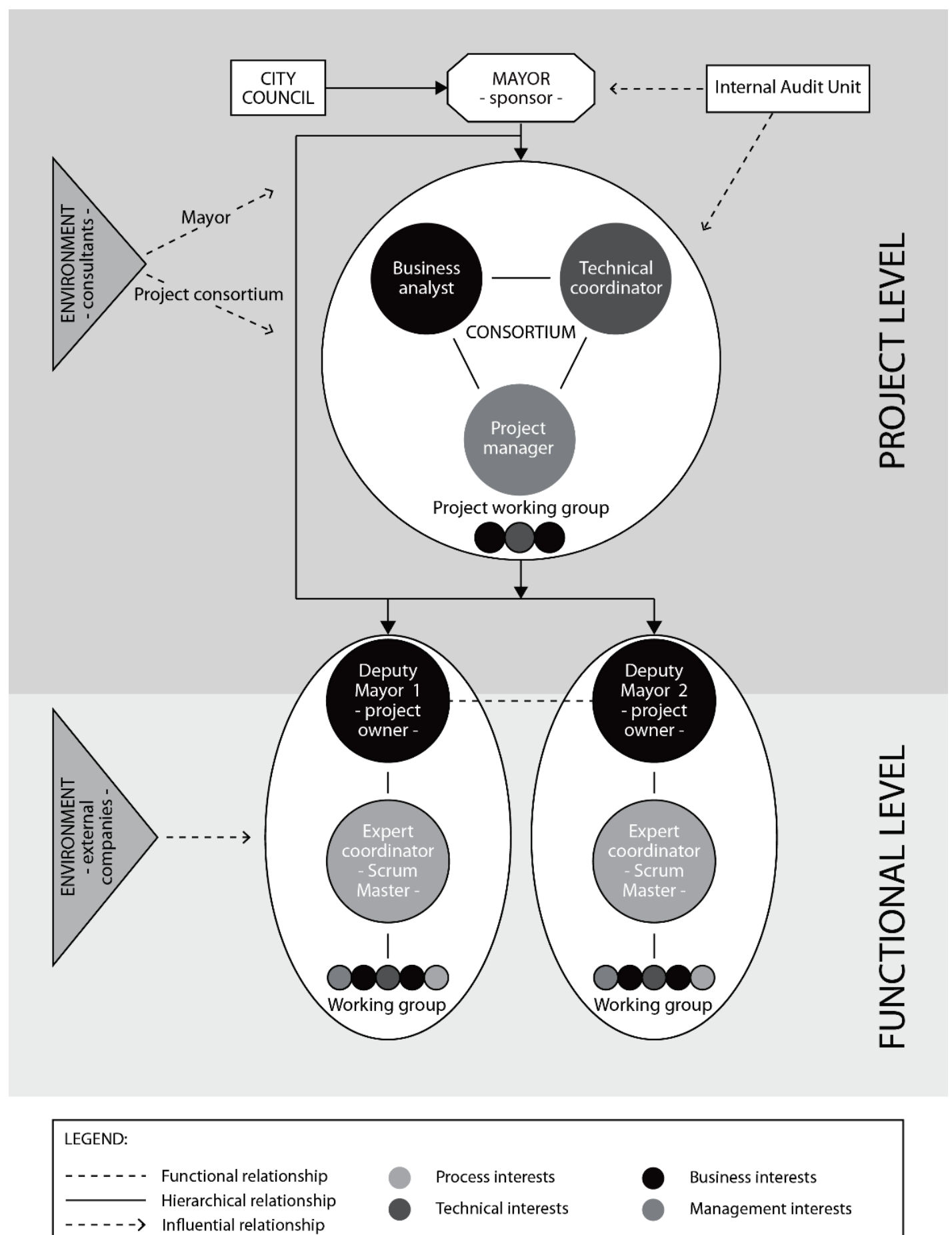

Figure 2 Agile organizational scheme of Hybrid Agile Model (authors developed according to [28]) 
The following features are expected to have a positive impact on the project development:

- Cyclic approach

- Interaction among participants

- Iterative delivery of "potentially deliverable products"

- Frequent testing results in delivering improved products.

Using Scrum method [19, 20] and DSDM framework [28], process management is defined by (1) defining roles and authority, and (2) an agile organizational scheme.

Operational implementation of projects is carried out according to the organizational scheme shown in Fig. 2. The agile organizational scheme of HAM takes into account project hierarchy levels (strategic, tactical, and operational) and projects" character as well as performance indicators by means of IPMA [2] or PMI [3] at the same time taking into account agile management principles, especially sprints, in order to give more flexibility and promptness into project environment. As agile sprints offers more efficient process application as well as iterative and incremental approach to all project phases this becomes the additional value to the proposed approach. Such synergy brings the best of both and therefore is called a hybrid. Another additional value is in its openness to environment on both project and functional level, in order to include necessary consultants during all stages of project life-cycle and especially during sprints.

The project level and the functional level ensure the integrity and compatibility of the strategic and operational realization of the project. In line with the LSGU business and development vision, the strategic level is ensured by the project level which is achieved through the integration of the business, technical and management aspect with the sponsorship role of the mayor and, possibly, with some other member of the city council.

Operational realization is ensured by the functional level that fulfils the vision of the project owner through iterative project deliveries on the principles of the Scrum working framework, i.e. through active interaction of interdisciplinary, cross-functional working groups. Tab. 1 shows the main roles, responsibilities and functions of internal and external participants, and the main activities of particular participants are listed below.

Table 1 Roles and responsibilities of stakeholders in LSGU projects according to the Hybrid Agile Model

\begin{tabular}{|c|c|c|c|c|c|}
\hline Stakeholder & Role & Responsibility & Key Functions & $\begin{array}{c}\text { Project } \\
\text { Consortium }\end{array}$ & \begin{tabular}{|c|}
$\begin{array}{c}\text { Functional } \\
\text { Level }\end{array}$ \\
\end{tabular} \\
\hline $\begin{array}{l}\text { Mayor/City } \\
\text { council }\end{array}$ & Sponsor & Realization of LSGU development strategy & Prioritization of projects & Yes & No \\
\hline Deputy Mayor & Project owner & Realization of project goals & Creation of PB & Yes & Yes \\
\hline $\begin{array}{l}\text { Internal Audit } \\
\text { Unit }\end{array}$ & Supervision & The regularity of project implementation & Regularity supervision, risk control & No & No \\
\hline Business analyst & $\begin{array}{c}\text { Represent } \\
\text { business interest }\end{array}$ & $\begin{array}{l}\text { Business vision and financial viability of the } \\
\text { project }\end{array}$ & $\begin{array}{l}\text { Monitoring of finances, ensuring } \\
\text { financial means }\end{array}$ & Yes & No \\
\hline $\begin{array}{c}\text { Technical } \\
\text { coordinator }\end{array}$ & $\begin{array}{c}\text { Ensures technical } \\
\text { solutions }\end{array}$ & Technical solution & Supervision of technical solutions & Yes & No \\
\hline Project manager & Runs the project & $\begin{array}{l}\text { Project management on Agile principles } \\
\text { (DSDM and Scrum framework) }\end{array}$ & $\begin{array}{l}\text { Project process management based } \\
\text { on Agile Principles }\end{array}$ & Yes & No \\
\hline $\begin{array}{l}\text { Project working } \\
\text { group }\end{array}$ & $\begin{array}{c}\text { Project } \\
\text { implementation }\end{array}$ & $\begin{array}{c}\text { Project deliveries in accordance with project } \\
\text { requirements }\end{array}$ & $\begin{array}{l}\text { Implementation of the project } \\
\text { consortium guidelines }\end{array}$ & Yes & No \\
\hline $\begin{array}{c}\text { Expert } \\
\text { coordinator }\end{array}$ & Scrum master & $\begin{array}{l}\text { Organizing and conducting workshops on the } \\
\text { principles of the Scrum working framework }\end{array}$ & Creating SB, conducting workshops & No & Yes \\
\hline Working group & $\begin{array}{c}\text { Process } \\
\text { implementation }\end{array}$ & Project deliveries through iterations & Participation in workshops & No & Yes \\
\hline $\begin{array}{c}\text { External } \\
\text { consultants }\end{array}$ & $\begin{array}{l}\text { Advising the } \\
\text { project } \\
\text { consortium and } \\
\text { sponsors }\end{array}$ & $\begin{array}{c}\text { Advisory support in defining the LSGU } \\
\text { development strategy through project } \\
\text { deliveries }\end{array}$ & $\begin{array}{l}\text { Advising sponsors and the project } \\
\text { consortium }\end{array}$ & Yes & No \\
\hline $\begin{array}{l}\text { External } \\
\text { companies }\end{array}$ & $\begin{array}{l}\text { Process } \\
\text { implementation }\end{array}$ & $\begin{array}{c}\text { Project deliveries in accordance with } \\
\text { contractual obligations and project } \\
\text { requirements }\end{array}$ & $\begin{array}{l}\text { Execution of contracted project } \\
\text { work within the agreed terms }\end{array}$ & No & Yes \\
\hline
\end{tabular}

\subsubsection{Project Level}

As seen in Fig. 2 and Tab. 1 almost all stakeholders are involved in project level. The Mayor, or, if necessary, one or more members of the City council have the role of the project sponsor. That depends on the nature, size and complexity of the project. The sponsor is responsible for project goals that must ensure the implementation of LSGU development strategy. The business analyst is in charge of financial analysis of the project throughout the life cycle and at each stage of the project. He/she monitors all project phases, takes care of resources allocation and controls deliveries, and participates in analysing and predicting changes within the project and supervises financial coverage for anticipated changes. The technical coordinator monitors the development of technical solutions within the project. In co-operation with the project working group, he/she proposes and advises on the necessary improvements for a particular project phase, and performs supervision of presented technical solutions and deliveries within the project.

Project manager, the licensed manager from the Project Management Department (PMD), is in charge of assisting the sponsor in defining project goals. He/she is responsible for overseeing the entire project, and cooperates with external consultants. On the other hand Project working group, among other activities, cooperates with the project level in developing the final iteration solution and participates in the analysis of technical and business aspects of iterative solutions and deliveries. It also participates in the development and alteration of Product Backlog as one of Scrums' artifacts. External consultants as the experts in specific fields assist the sponsor in defining project goals as well as help to align project goals with LSGU strategic goals. They also provide advice to the members of the project consortium. 


\subsubsection{Functional Level}

On functional level (Fig. 2 and Tab. 1) Deputy Mayors assume the role of the project owner according to the areas and subject of the project. They take part in the development of Product Backlog taking into account the business vision and strategy. Thereby, they collaborate with members of the project consortium. In co-ordination with the project manager and the expert coordinator (Scrum Master) they participate, if necessary, in project workshops and analysis of business and technical aspects of iterative solutions. They are responsible to the Mayor for their work. In order to fulfil project objectives, they cooperate with the project consortium, in particular with the project manager and project work team. Expert coordinator cooperates with the project manager and executes operational decisions of the project manager. $\mathrm{He} / \mathrm{she}$ also leads Scrum workshops, and coordinates and participates in the design of all Scrum artefacts. Working group participates in sprint planning, performs activities according to Scrum artefacts (i.e. Sprint Backlog), participates in the creation of Scrum artefacts and participates in Scrum workshops. External companies participate in working group activities in accordance with the contractual obligations.

\subsection{Financing, Human Resources and IT Support}

Proposed solutions require adequate sources of funding. It is up to the leaders to find satisfactory legal solutions by redistributing funds within the budget. This is a very important element because financial motivation and support are an essential factor of success. As a rule, opportunities exist, and solutions depend on the skilfulness and the will of leaders to find and apply them. An additional option are the available EU funds. One of the goals of the Law is to "... make the most efficient use of the European Union funds" especially through active participation in the councils foreseen by it. When discussing human resources, the emphasis is placed on education. Education must enable participants to learn about Agile principles, matrix structure, and dual responsibility. The goal is a constant training so that the participants could develop a common vision and value system [30]. Formal training and clearly predefined roles within the matrix structure are required. In the context of information support, one of the basic elements is the development of a communication plan. The communication plan gives an answer to the question which information is needed for particular groups within the organization. The plan defines roles in the communication system (creation, distribution of information and persons to be informed).

\subsection{Anticipated Obstacles of HAM Implementation}

The obstacles occurring during the implementation of Hybrid Agile Model characterized by its more flexible working framework are particularly accentuated. Bulatović [26] identifies areas where they can occur:

- Adjustment of the functional organizational structure to a more flexible framework

- Organization of roles within the working framework

- The question of individual responsibility

- Evaluation of project progress and success
Promotion of cross-functional communication

- $\quad$ Alignment of Agile practice with LSGU regulations.

\section{CASE STUDY - CITY OF POREČ}

The basic theory is that the existing functional organizational structure in the LSGU does not adequately support the successful implementation of the projects. The problem is getting even more pronounced by the increase in the number of projects, which is largely due to the withdrawal of financial resources from EU funds. Construction projects make up a large part, especially communal infrastructure projects. By integrating the matrix organizational structure with the organization of work processes on Agile principles, significantly better conditions for successful project implementation would be ensured.

To prove this theory, Yin's case study methodology [31] was applied. The required data was collected by a semi-structured interview method and by studying the available documentation. Interviews were conducted with key participants of the LSGU City of Poreč.

\subsection{Overview of the Present Situation}

According to the latest census [32], 16,696 inhabitants live in the City of Poreč, which is therefore classified into a group of medium sized towns. According to CBS [33] towns in the Republic of Croatia are seen as large (over 50,000 inhabitants), medium (from 10,000 to 50,000 inhabitants), and small (under 10,000 inhabitants) size. In addition to the fact that medium sized towns represent $46 \%$ of the total number of cities in the Republic of Croatia, the selected city is an exemplary representative for the introduction and application of the model for three reasons:

- Due to its size, the city/city administration is set up in the same way as in larger cities (towns with over 50,000 inhabitants) in the Republic of Croatia.

- Due to the smaller number of people in city administration, it is more flexible and ready to change, i.e. to implement and apply new management models. - The average GDP per capita of the region in which the city of Poreč is located is higher than all regions of the Republic of Croatia (GDP per capita of the Istrian County is $12,724 €$, while the GDP per capita of the Republic of Croatia is $10,152 €[33])$.

Moreover, the City of Poreč has been chosen as a representative example and a leader among the small and medium sized cities in view of the highly developed tourism industry. This entails a large number of projects intended for the construction of tourist facilities and supporting infrastructure facilities.

It is necessary to emphasize the capacity and the readiness of the Poreč City Administration to improve the organizational structure with the aim to furtherly support the development of the environment both in tourism and in other economic sectors. Therefore, the City of Poreč is optimal for the application and testing of the proposed model. Cities of a similar size, but less developed, can apply the model gradually, in multiple stages, according to their capabilities. A small number of projects is being implemented in these cities, which is a mitigating circumstance for the implementation of the model. 
According to the Act and data [32, 33], Poreč is above the average in development with tourism as the most important economic branch. In addition to tourism, primary activities are agriculture, trade and construction. Although tourism is the leading branch in the city of Poreč, there is still a significant space for development in the tourism sector itself, especially in the development of off-season offer, but there is also an inevitable need for diversification of activities to reduce the seasonal impact of tourism on the overall economy of the region. The increased development of all-year tourism is related to the development and diversification of tourist offer. Such is enabled through appropriate construction investment projects in tourist facilities and accompanying infrastructure and other related facilities. The present development and needs for an even more rapid progress generate and seek adequate changes. Therefore, there is an increasing need for a faster adaptation to the dynamic development of the wider community in withdrawing financial resources from EU funds. Like in other LSGUs in the Republic of Croatia, there are enough inherent problems that have already been explained in the light of the situation in LSGUs, where there is certainly room for improvement [27, 29]. A more flexible management framework would better suit the required changes.

\subsection{Present Organizational Structure and Problems}

As usual among LSGUs in the Republic of Croatia, the existing organizational structure in the City of Poreč is of a functional character in accordance with the valid legal framework. The present functional organizational scheme is shown in Fig. 3.

The existing organizational and management framework is insufficiently flexible for a large number of changes caused by accelerated development and an increasing number of investment construction projects. On the other hand, projects are indispensable for further development and progress.

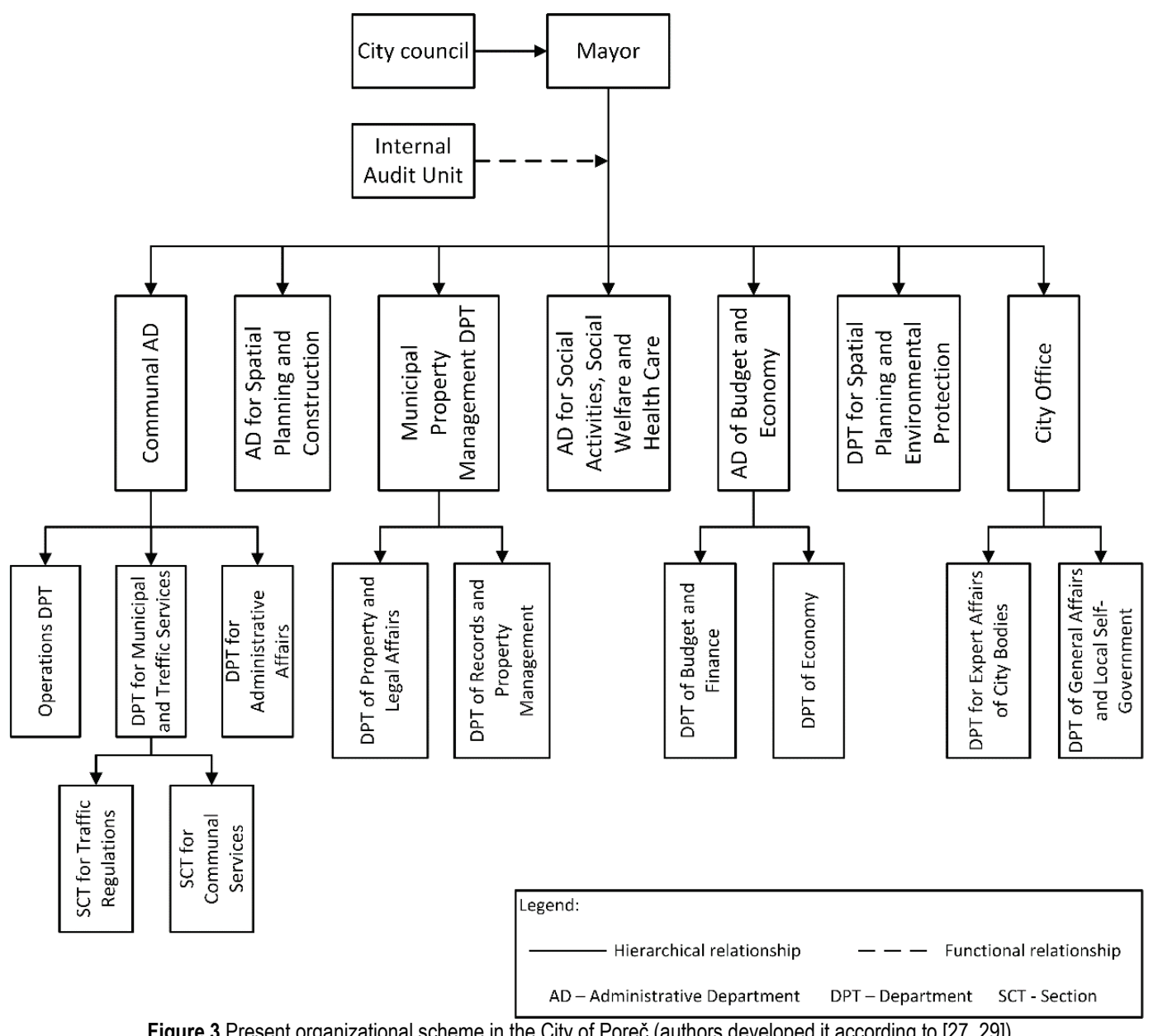

The existing functional organizational structure is not suitable for project implementation for the following main reasons:

- Effect of "silos" - functioning as a closed unit within a department where changes are not welcome

- Lack of lateral connections between departments

- Communication difficulties between departments

- No multidisciplinary approach

- Organizational obstacles when involving staff from departments into projects
- Lack of adequate PM knowledge (the existing organization is not favourable for the acquisition or use of such knowledge)

- There is no Procurement Department.

The lack of a Procurement Department is a major drawback. This is particularly the case with the implementation of public procurement procedures according to the Public Procurement Act (Official Gazette NN 120/16). 


\subsection{Implementation of the New Hybrid Agile Model}

Identified problems can be solved by introducing the proposed Hybrid Agile Model which provides the following:

- Introduction of matrix organizational structure

- Establishment of the Project Management Department (PMD)

- Establishment of the Procurement Department (PD)

- A division of the Administrative Department of Budget and Economy into the Administrative Department of Economy and the Administrative Department of Budget

- Project management education

- Establishment of a project consortium

- By introducing Agile's working framework into the work processes related to project implementation (according to the scheme in Fig. 2).

Transformation of the functional organization into matrix (Fig. 4) is suggested, which is considered to better respond to project challenges, especially due to horizontal linking of departments and involvement of staff in projects. With regard to the implementation of construction projects, the establishment of lateral functional links and the involvement of staff in projects specifically refers to Department for Spatial Planning and Environmental Protection and Municipal Property Management Department. Innovative solutions based on the integral approach are introduced.

As seen in Fig. 4, the biggest innovation is the Project Management Department (PMD), which is designed as a special unit with the task of organizing workgroups for project management and promoting the Agile principles within the organization. The link between PMD and other administrative departments is functional, while it still maintains a vertical link with the Mayor and Deputy Mayors. If required by the project, the PMD recruits staff from other administrative departments that together form an interdisciplinary cross-function group according to the Agile model. The project link covers all levels of management, the Internal Audit Unit, Deputy Mayor and administrative departments, the Mayor and the City council outside of this relationship as a kind of sponsor. Traditional project management offices rely on traditional project management, while the proposed PMD applies also Agile principles. In this sense Agile approach provides a natural fit for the need for phased implementation where there is a policy directive that must be implemented urgently. To do so, it is essential to establish a procurement department. Procurement is an important segment of project implementation, and the City of Poreč, as well as all LSGUs, are liable to the Public Procurement Act. The staff from the PD is assigned to the projects and participates in the projects as part of the project team. The Administrative Department of Budget and Economy is divided into two administrative departments, one for the economy and the other for the budget, primarily because of the nature and complexity of the job.

The matrix structure also has its shortcomings - a sense of discomfort with employees due to the loss of sense of security in the parent department, responsibility to the project manager, need for greater engagement and adaptation to changes, and other.
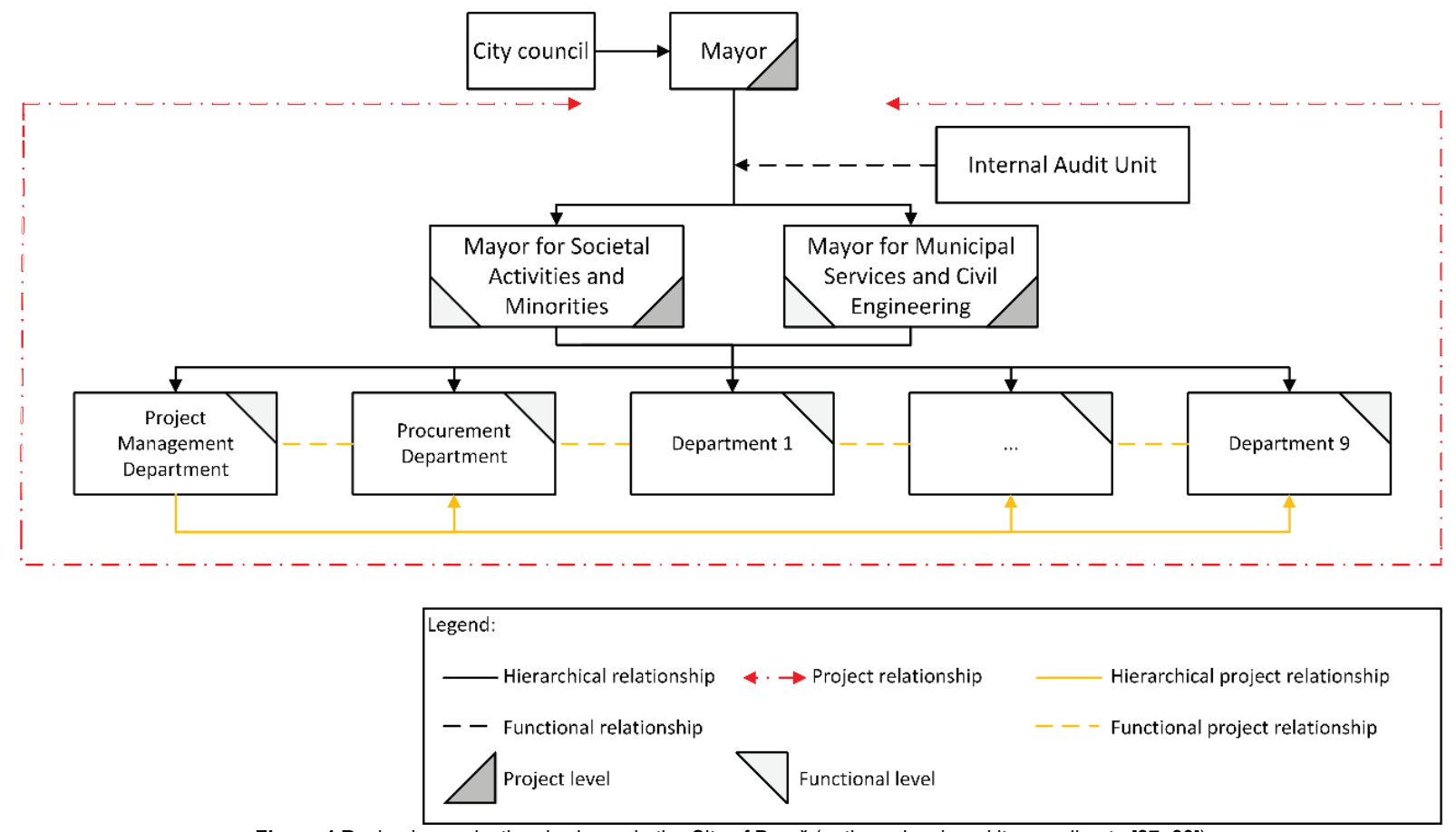

Figure 4 Revised organizational scheme in the City of Poreč (authors developed it according to [27, 29])

Within the matrix scheme, the agile work scheme is defined with the roles and powers according to Scrum and DSDM framework shown in Fig. 4. The role of the sponsor is taken over by the Mayor, alone or with certain city council members, depending on their areas of jurisdiction. The scheme defines the composition, function and relationship between the project and the functional level.
The project consortium defines the business, technical and management aspects of the project. Advisory role, if required, is provided by external consultants and the Internal Audit Unit in relation to checking the regularity of the decisions. The project manager is the link between the project and the functional level. Together with the sponsor and project consortium, the project manager defines the 
project, is also in charge of overseeing it and co-operating with the consultants and determines the required amount of information given to the participants. Functioning of the process at the functional level follows the principles and practice of the Scrum method. At the functional level, the Deputy Mayors are owners of the product. The expert coordinator i.e. the Scrum Master is appointed. The interdisciplinary working group has project and functional tasks and responsibilities.

\subsection{Implementation Assessment of the Proposed Model}

By applying the Hybrid Agile Model, all of the identified negative circumstances would be resolved or significantly improved. These are, i.e., lack of formal lateral functional links between the departments and sections, lack of communication between departments, lack of interdisciplinary approach, difficulty of including staff from other departments in projects and insufficient knowledge about project management. These problems are particularly pronounced in the projects implemented in functional organizational structures. Using a hybrid model by introducing the Agile principles significantly improves the quality and efficiency of project implementation, especially by introducing project and functional levels, assigning appropriate roles to project consortium members on DSDM framework, and accelerating execution and interaction among participants through Scrum iterations.

The present state of the observed example enables the model to be applied. The model characteristics allow adjustments and improvements over time. At the conceptual level, Hybrid Agile Model can be applied to local government units of similar characteristics with reasonable adaptation to the given specific circumstances. If necessary, incremental approach should be applied.

Possible sense of discomfort and possible resistance to change with employees due to loss of sense of security in the parent department due to matrix organization, answering to the project manager, the need for greater engagement and adaptation to changes can be expected in the initial stage of hybrid model implementation. Education, motivation, effective implementation of the model in practice and adequate reward for project work will mitigate these negative initial effects.

\section{CONCLUSIONS}

The research has shown that the existing functional way of organizational structure of local self-government units does not suit the project requirements, especially in the circumstances of increasing the number of projects (mostly construction and infrastructure projects). These facts point out the need for changes in the organizational structure as well as in the approach to project management and work process organization. The usual matrix structure, which is commonly applied in solving this problem, is also not the right answer. Multidisciplinary approach, clear and fast communication channels, lateral connections between departments are just some of the prerequisites for more efficient project management and additional organizational development. The idea is that the matrix structure could be significantly improved by organizing business processes based on the Agile framework. In this sense Agile approach provides a natural fit for the need for phased implementation where there is a policy directive that must be implemented urgently.

Based on this thinking, a Hybrid Agile Model was suggested. The Model integrates matrix organizational structure with Agile working framework combining project and functional levels based on Scrum and DSDM framework. By applying the Hybrid Agile Model, all of the identified negative circumstances present in the local selfgovernment unit functional organizational structure expressed in project implementation and project management would be resolved or significantly mitigated as proven by case study on the example of the City of Poreč. Particularly emphasized is the lack of formal and actual lateral functional relationships between departments, difficult recruitment of staff from the departments in the project teams and poor organization, insufficient dynamics and efficiency of work processes in the execution of project activities. Under the current circumstances in the Republic of Croatia, Hybrid Agile Model can be introduced within the scope of the applicable legal regulations with the foreseeably reasonable use of financial resources.

\section{Acknowledgements}

This work has been fully supported by the University of Rijeka under the project number uniri-tehnic-18-125.

\section{REFERENCES}

[1] Public Administration Development Strategy for the period 2015-2020. Retrieved from http://narodne-novine.nn.hr/ clanci/sluzbeni/2015_06_70_1329.html https://doi.org/10.1111/anae.13279

[2] IPMA. 2018. Individual Competence Baseline for Project Management (ICB 4.0), International Project Management Association, Zurich, Switzerland.

[3] PMI, (2013). A Guide to Project Management Body of Knowledge (PMBOK). Newton Square: Project Management Institute.

[4] Jajac, N., Knezić, S., \& Babić, Z. (2010). Integration of multicriteria analysis into decision support concept for urban road infrastructure management. Croatian Operational Research Review, 1, 74-83.

[5] Jajac, N., Bilić, I., \& Alduk, A. (2013). Decision support concept to management of construction projects - problem of construction site selection. Croatian Operational Research Review, 4, 235-246.

[6] Marović, I., Car-Pušić, D., \& Hrvatin, Z. (2014). Establishing a model to evaluate public administration projects. Electronic Journal of the Faculty of Civil Engineering Osijek, 5(8), 56-66. https://doi.org/10.13167/2014.8.7

[7] Marović, I., Završki, I., \& Jajac, N. (2015). Ranking zones model - a multicriterial approach to the spatial management of urban areas. Croatian Operational Research Review, 6(1), 91-103. https://doi.org/10.17535/crorr.2015.0008

[8] Car-Pušić, D., Marović, I., Gudac, I., \& Medvedec, D. (2015). Prioritization of public investment projects: Case study of GSC portfolio. Proc. of $34^{\text {th }}$ Int. Conf. on Organizational Science Development "Internationalization and cooperation", March 25-27 2015, Portorož, Slovenia.

[9] Rogulj, K. \& Jajac, N. (2018). Achieving a construction barrier-free environment: decision support to policy selection. Journal of Management in Engineering, 34(4), 04018020 .

https://doi.org/10.1061/(ASCE)ME.1943-5479.0000618 
[10] Šandrk Nukić, I., Galić, M., \& Dolaček-Alduk, Z. (2015). Impact of changes in a project team structure on the team performance. Electronic Journal of the Faculty of Civil Engineering Osijek, 5(10), 58-66. https://doi.org/10.13167/2015.10.7

[11] Agile Manifesto, (2001). Retrieved from http://agilemanifesto.org/

[12] Vinekar, V., Slinkman, C. W., \& Nerur, S. (2006). Can agile and traditional systems development approaches coexist? An ambidextrous view. Information Systems Management, 23(3), 31-42.

https://doi.org/10.1201/1078.10580530/46108.23.3.20060601/937 05.4

[13] Mao, P., Li, S., Ye, K., \& Cai, H. (2017). A field theory based model for identifying the effect of organizational structure on the formation of organizational culture in construction projects. KSCE Journal of Civil Engineering, 21(1), 45-53. https://doi.org/10.1007/s12205-016-1233-7

[14] Lindsjorn, Y., Sjoberg, D. I. K., Dingsoyr, T., Bergersen, G. R., \& Dyba, T. (2016). Teamwork quality and project success in software development: A survey of agile development teams. The Journal of Systems and Software, 122, 274-286. https://doi.org/10.1016/j.jss.2016.09.028

[15] Ribeiro, F. L. \& Fernandes, M. T. (2010). Exploring agile methods in construction small and medium enterprises: a case study. Journal of Enterprise Information Management, 23(2), 161-180. https://doi.org/10.1108/17410391011019750

[16] Owen, R., Koskela, L. J., Henrich, G., \& Codinhoto, R. (2006). Is agile project management applicable in construction. Proceedings for the $14^{\text {th }}$ Annual Conference of the International Group for Lean Construction, Santiago, Chile, 51-66.

[17] Saini, M., Arif, M., \& Kulonda, D. J. (2018). Critical factors for transferring and sharing tacit knowledge within lean and agile construction processes. Construction Innovation, 1(1), 64-89. https://doi.org/10.1108/Cl-06-2016-0036

[18] Streule, T., Miserini, N., Bartlome, O., Klippel, M., \& Garcia de Soto, B. (2016). Implementation of Scrum in the construction industry. Procedia Engineering, 164, 269-276. https://doi.org/10.1016/j.proeng.2016.11.619

[19] Sutherland, J. \& Schwaber, K. (2011). The Scrum Papers: Nut, Bolts, and Origins of an Agile Framework. Retrieved from https://www.scrumguides.org/docs/scrumpapers.pdf

[20] Schwaber, K \& Sutherland, J. (2013). The Definitive Guide to Scrum: The Rules of the Game. Retrieved from https://www.scrumguides.org/docs/scrum-guide-us.pdf

[21] Sweetman, R. \& Conboy, K. (2018). Portfolios of agile projects: a complex adaptive systems' agent perspective. Project Management Journal, 49(6), 18-38. https://doi.org/10.1177/8756972818802712

[22] Boer, A. \& van Engers, T. (2013). Agile: a problem-based model of regulatory policy making. Artificial Intelligence and Law, 21, 399-423. https://doi.org/10.1007/s10506-013-9144-0

[23] Nuottila, J., Aaltonen, K., \& Kujala, J. (2016). Challenges of adopting agile methods in a public organization. International Journal of Information Systems and Project Management, 4(3), 65-85.

[24] Simoyama, F. de O., Bueno, R. L. P., \& Battisti, M. C. G. (2016). Adaptation and implementation of scrum methodology for agile projects in a government agency. Journal of Management \& Technology, 16(2), 260-276.

[25] Lappi, T., Karvonen, T., Lwakatare, L. E., Aaltonen, K., \& Kuvaja, P. (2018). Toward an improved understanding of agile project governanace: a systematic literature review. Project Management Journal, 49(6), 39-63. https://doi.org/10.1177/8756972818803482

[26] Narbon-Perpina, I. \& De Witte, K. (2018). Local governments' efficiency: a systematic literature review-part
I. International Transactions in Operational Research, 25, 431-468. https://doi.org/10.1111/itor.12364

[27] Car-Pušić, D., Marović, I., \& Bulatović, G. 2019. Agile organizational model for managing local government projects. Electronic Journal of the Faculty of Civil Engineering Osijek, 9(18), 12-21. https://doi.org/10.13167/2019.18.2

[28] Agile Business Consortium, (2014). The DSDM Agile Project Framework.

Retrieved from https://www.agilebusiness.org/

[29] Bulatović, G. (2015). Implementation of the Hybrid Agile Organizational Structure in Local Government Units. Graduation thesis. Rijeka: Faculty of Civil Engineering, 72.

[30] Sy, T., Beach, L., \& D'Annunzio, L. S. (2005). Challenges and Strategies of Matrix Organizations. Human Resource Planning, 28(1), 39-48.

[31] Yin, R. K. (2014). Case Study Research: Design and Methods. Sage Publications, Thousand Oaks, CA.

[32] CBS - Croatian Bureau of Statistics, (2013). Census of Population, Households and Dwellings 2011, Statistical Reports, Zagreb. Retrieved from http://www.dzs.hr/

[33] CBS - Croatian Bureau of Statistics, (2013). Gross Domestic Product per capita for Republic of Croatia, at nuts 2013 - 2nd Level and Countries, Statistical Reports, Zagreb. Retrieved from http://www.dzs.hr/

\section{Contact information}

Diana CAR-PUŠIĆ, PhD

(Corresponding author)

University of Rijeka, Faculty of Civil Engineering,

Radmile Matejčić 3, 51000 Rijeka, Croatia

E-mail: diana.car.pusic@gradri.uniri.hr

Ivan Marović, $\mathrm{PhD}$

University of Rijeka, Faculty of Civil Engineering,

Radmile Matejčić 3, 51000 Rijeka, Croatia

E-mail: ivan.marovic@gradri.uniri.hr

Goran BULATOVIĆ, mag.i ing. aedif.

Exprimo d.0.0.

Jasenova 6, 52440 Poreč, Croatia

E-mail: goranbulatovic@zoho.com 